schale so lange, bis sie erweicht, setzt dann circa 15 Tropfen verdünnte Schwefelsäure ( $1 \mathrm{Th}$. Säure und $5 \mathrm{Th}$. W.) zu und untersucht von Zeit zu Zeit einen Tropfen mit Jodlösung. Wird letztere nicht mehr verändert, zeigt sich selbst nicht mehr die weinrothe Färbung des Dextrins, so dampft man zur Sýrupsdicke ab und bringt die Flüssigkeit in das eine Kölbchen eines alkalimetrischen Apparates von Fresenius und Will, indem man zunächst die freie Säure durch eine concentrirte Lösung von weinsteinsteinsaurem Kali abstumpft und den Apparat wägt. Hierauf setzl man etwa $20 \mathrm{Grm}$. frischer Hefe zu und stellt denselben an einen Ort, der möglichst auf einer Temperatur von $25^{\circ} \mathrm{C}$. ungefähr vier bis fünf Tage erhalten wird. Die Kohlensäure geht dann durch eine kleine Menge Schwefelsäure, die in dem andern Kölbchen, welches mitgewogen, enthalten ist, um sie von dem Wassergehalte und dem etwa entweichenden Weingeistdampf zu befreien. Zur Correction hat man dann noch einen ganz gleichen Apparat bloss mit $20 \mathrm{Grm}$. Hefe, um die hierin suspendirte Kohlensäure zu bestimmen.

Als Thatsache wird der Berechnung vorausgesetzt, dass für 1 Aeq. Stärke $=\mathrm{C}^{2}{ }^{2} \mathrm{H}^{10} \mathrm{O}^{10} \&$ Aeq. Kohlensäure entweichen, welches auch ein genauer Versuch mit reiner Stärke bestätigte. (Ann. d. Chemie u. Pharm. Bd.58. p. 212 - 227.) $\mathrm{Hz}$.

\title{
Harnstoff im Fruchtwasser.
}

Wöhler fand in dem Fruchtwasser, welches aus der Blase, die unverletzt vor der Geburt des Kindes herausgetreten war, Harnstoff, woraus derselbe folgert, dass schon in den Nieren des. Fölus Harnstoff ausgesondert wird, noch the er Nahrung zu sich genommen hat. - Uebereinstimmend hiermit ist eine andere von Wöhler gemachte Beobachtung, dass ein kleiner Nierenstein von einem vor der Zeit und todtgeborenen Fötus aus Harnsäure bestand. (Annal.der Chem. u. Pharm. Bd.58. p.98.) 